\title{
Arylesterase activity of paraoxonase 1 in patients with primary hypertension
}

\begin{abstract}
Aleksandra Baszczuk', Ewa Wysocka ${ }^{1}$, Alicja Płóciniczak ${ }^{1}$, Anna Thielemann¹, Anna Dżumak¹, Karolina Hoffmann², Sławomir Michalak ${ }^{3}$, Wiesław Bryl²
\end{abstract}

${ }^{1}$ Department of Laboratory Diagnostics, Poznań University of Medical Sciences, Poznań, Poland

${ }^{2}$ Department of Internal Medicine, Hypertension and Metabolic Disorders, Poznań University of Medical Sciences, Poznań, Poland

Abstract $\quad{ }^{3}$ Department of Neurochemistry and Neuropathology, Poznań University of Medical Sciences, Poznań, Poland

Introduction. Paraoxonase 1 is an enzyme associated with high-density lipoprotein fraction and is considered to present antioxidant activity.

Objectives. The aim of the study was to assess the arylesterase activity of paraoxonase 1 (PON1) in the serum of patients with hypertension, due to effect of therapy and before treatment.

Patients and Methods. The study was conducted in 76 patients with primary hypertension and 28 volunteers for the control group. Hypertensive subjects were assigned to one of three groups: well controlled $(n=25)$, poorly controlled $(n=26)$, and newly diagnosed before therapy $(n=25)$ hypertension. We evaluated metabolic parameters in all participants using routine laboratory methods, as well as arylesterase activity of PON1.

Results. The four study groups differed with arylesterase activity of PON1 and the highest levels were found in patients with well controlled hypertension and the lowest in newly diagnosed. All patients diagnosed with hypertension presented negative correlations between PON1 and systolic and diastolic blood pressure.

Conclusions. Effective treatment of hypertension could result in increased PON1 activity, despite unfavorable homocysteine concentrations in blood. Untreated hypertension might decrease activity of PON.

\section{Introduction}

Hypertension frequently accompanies lipid disorders and together they lead to the development of atherosclerosis and chronic heart failure [1, 2]. Dyslipidemia causes not only changes of concentrations of lipoprotein particles, but also their function. One of the factors affecting high-density lipoprotein (HDL) is paraoxonase 1 (PON1, EC 3.8.1). The activity of this enzyme can prevent the oxidation of lipoproteins and contribute to slowing down the development of atherosclerosis [3].

The PON1 protein is synthesized in the liver and excreted into the plasma, where it binds to HDL particles with the hydrophobic $\mathrm{N}$-terminal end. PON1 is a glycoprotein consisted of 254 amino acids, from which, during secretion and maturation, $\mathrm{N}$-terminal methionine is removed. A signal sequence is essential for binding of PON1 with HDL particles. PON1 exhibits affinity to multiple substrates and shows the activity of arylesterase, paraoxonase, and thiolactonase, together with substantial activity against oxidized eicosanoids and docosanoids, which are the products of transformations of unsaturated fatty acids. PON1 can hydrolyze compounds, such as phospholipid peroxides, hydrogen peroxide, and also oxidized lipid residues of oxidized low-density lipoprotein (oxLDL) in atherosclerotic plaque and macrophages [4]. The exact mechanism of this action is not clear. Researchers suggest that PON1 exhibits the activity similar to peroxidases because the incubation of oxidized LDL with cleaned 
PON1 lowers the concentration of cholesteryl linoleate hydroperoxides (CL-OOH) up to $90 \%$ [5].

The activity of PON1 is genetically conditioned. Several polymorphisms of PON1 gene are distinguished - L55M, Q192R, and T(-108)C - which modulate the activity of this enzyme.

Besides genetic polymorphism, such factors as diet, lifestyle, diseases, and metabolic disorders can influence the activity of PON1 [4].

The main aim of the study was to assess the arylesterase activity of paraoxonase 1 (PON1) in the serum of patients with hypertension, due to the effect of therapy, and before treatment.

\section{PATIENTS AND METHODS}

We studied consecutive patients with primary hypertension diagnosed according to ESH/ESC (European Society of Hypertension/European Society of Cardiology) guidelines. The exclusion criteria were as follows: secondary hypertension; a history of myocardial infarction, stroke, and any surgical procedure in the previous 6 months or any acute illness in the last 3 months; as well as the diagnosis of diabetes, kidney and urinary tract diseases, liver damage, hormonal disorders, neurological diseases, psoriasis, and neoplastic disease. Subjects were enrolled in the study based on medical examination and laboratory test results. Participants did not report smoking and abusing alcohol as well as using antihyperlipidemic treatment. Persons with abnormal results of routine urinalysis and complete blood count, and elevated concentrations of serum creatinine and C-reactive protein (hsCRP higher than $10 \mathrm{mg} / \mathrm{l}$ ), were excluded from the study.

We investigated 76 patients aged 30 to 71 years (51 males, 25 females) with primary hypertension, who were divided into three groups: 25 patients with newly diagnosed hypertension (group 1), 26 patients with poorly controlled hypertension (group 2), and 25 patients with well controlled hypertension (group 3).

The newly diagnosed patients, who did not take any medication yet, were enrolled in group 1 . The patients suffering from hypertension for 6-9 months, who had undergone antihypertensive treatment were considered for group 2 or 3 . The therapy included: alpha blocker (alphareceptor blocker), beta blocker (beta-receptor blocker), calcium channel blocker, diuretic, ACE (angiotensinconverting enzyme) inhibitor or angiotensin receptor blocker, used both in monotherapy and combined therapy (2 to 5 drugs) (Table 1). The goal of antihypertensive treatment was to achieve blood pressure below 140/90 $\mathrm{mmHg}$, which was effective in $49 \%$ of participants. Group 2 consisted of patients who had not achieved the therapeutic goal in the last 3 months. Group 3 consisted of patients who had achieved the therapeutic goal for the last 3 months.

The control group (group 0) consisted of 28 persons aged 32 to 70 years (15 males, 13 females), with no hypertension and cardiovascular disease, who followed the exclusion criteria listed above. The persons from the control group were free of any medications.

The study protocol was accepted by the Bioethics Committee of Poznan University of Medical Sciences, Poland (statement No. 55/15), according to the Declaration of Helsinki for Human Research. All patients obtained information about the procedure and signed the informed consent to participate in the study.

We withdrew fasting venous blood using the S-Monovette ${ }^{\circledR}$ blood collection system (Sarstedt, Nümbrecht, Germany) for complete blood count and biochemistry tests. The latter was preceded by centrifugation of the blood sample at $3500 \times \mathrm{g}$ for 10 minutes. Serum samples for determination of PON1 activity were isolated and stored at $-80^{\circ} \mathrm{C}$ until assay.

The arylesterase activity of PON1 was measured using phenylacetate as a substrate (Sigma-Aldrich, St Louis, Missouri). Initial rates of hydrolysis were determined

Table 1. The applied antihypertensive treatment in patients with poorly controlled and well controlled hypertension. Data are presented as numbers and percentages of patients undergoing the indicated treatment (in parenthesis)

\begin{tabular}{|c|c|c|}
\hline & $\begin{array}{l}\text { Patients with poorly } \\
\text { controlled hyperten- } \\
\text { sion } \\
n=26\end{array}$ & $\begin{array}{l}\text { Patients with well con- } \\
\text { trolled hypertension } \\
\qquad n=25\end{array}$ \\
\hline Alpha blocker & $\begin{array}{c}1 \\
(4 \%)\end{array}$ & $\begin{array}{c}2 \\
(8 \%)\end{array}$ \\
\hline Beta blocker & $\begin{array}{c}16 \\
(62 \%)\end{array}$ & $\begin{array}{c}13 \\
(52 \%)\end{array}$ \\
\hline $\begin{array}{l}\text { Calcium channel } \\
\text { blocker }\end{array}$ & $\begin{array}{c}12 \\
(46 \%)\end{array}$ & $\begin{array}{c}12 \\
(48 \%)\end{array}$ \\
\hline Diuretic & $\begin{array}{c}16 \\
(62 \%)\end{array}$ & $\begin{array}{c}13 \\
(52 \%)\end{array}$ \\
\hline ACE inhibitor & $\begin{array}{c}10 \\
(39 \%)\end{array}$ & $\begin{array}{c}11 \\
(44 \%)\end{array}$ \\
\hline $\begin{array}{l}\text { Angiotensin receptor } \\
\text { blocker }\end{array}$ & $\begin{array}{c}7 \\
(27 \%)\end{array}$ & $\begin{array}{c}7 \\
(28 \%)\end{array}$ \\
\hline Mono-therapy & $\begin{array}{c}6 \\
(23 \%)\end{array}$ & $\begin{array}{c}6 \\
(24 \%)\end{array}$ \\
\hline 2-drug therapy & $\begin{array}{c}7 \\
(27 \%)\end{array}$ & $\begin{array}{c}9 \\
(36 \%)\end{array}$ \\
\hline 3-drug therapy & $\begin{array}{c}10 \\
(39 \%)\end{array}$ & $\begin{array}{c}7 \\
(28 \%)\end{array}$ \\
\hline 4-drug therapy & $\begin{array}{c}3 \\
(11 \%)\end{array}$ & $\begin{array}{c}2 \\
(8 \%)\end{array}$ \\
\hline 5-drug therapy & $\begin{array}{c}0 \\
(0 \%)\end{array}$ & $\begin{array}{c}1 \\
(4 \%)\end{array}$ \\
\hline
\end{tabular}




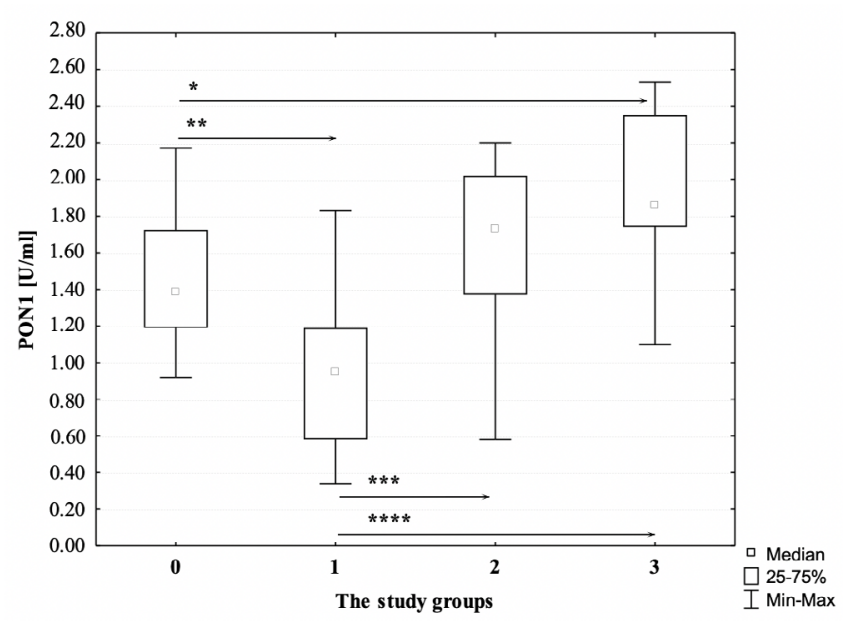

Figure 1. The comparison of arylesterase activity of paraoxonase 1 (PON1) among study groups, (0) - control group, (1) - patients with newly diagnosed hypertension, (2) - patients with poorly controlled hypertension, (3) - patients with wellcontroled hypertension: Kruskal-Wallis ANOVA by Ranks $p<0,0001$ and post hoc Dunn test analysis:

${ }^{*}(0)$ vs (3) $p=0.0005 ;{ }^{* *}(0)$ vs (1) $p=0.0238 ;{ }^{* * *}(1)$ vs (2) $p<0.0001$ $* * *$ (1) vs (3) $p<0.0001$

spectrophotometrically at $270 \mathrm{~nm}$ and $25^{\circ} \mathrm{C}$. The assay mixture consisted of $1.0 \mathrm{mmol} / \mathrm{l}$ phenylacetate and $0.9 \mathrm{mmol} / \mathrm{l}$ $\mathrm{CaCl}_{2}$ in $20 \mathrm{mM}$ Tris $\mathrm{HCl}, \mathrm{pH}$ 8.0. The coefficient of variation $4.26 \%$ described the precision of the method. One unit of arylesterase activity equates to $1 \mu \mathrm{mol}$ of phenylacetate hydrolyzed per minute (U).

Otherlaboratory tests were performed, using analyzers and reagents manufactured by Siemens Healthcare Diagnostics (Deerfield, IL, USA). We determined complete blood count on the ADVIA2120i analyzer. The serum concentrations of total cholesterol (T-C), LDL-cholesterol (LDL-C), HDL-cholesterol (HDL-C) and triglycerides (TG), high sensitivity C-reactive protein (hsCRP), creatinine, sodium, and potassium were assessed using the Dimension Xpand Plus analyzer. The concentration of homocysteine in serum was determined using an immuno-chemiluminescence method on the ADVIA Centaur XP analyzer. The tests were performed regarding the principles of Good Clinical Laboratory Practices.

All statistical analyses were performed using STATISTICA 10.0 PL (Stat Soft Inc., Tulsa, Oklahoma, United States). The normality of the data distribution was tested by ShapiroWilk test. Subsequently, the Kruskal-Wallis test and post hoc Dunn test were applied to compare the activity of PON1 and concentrations of examined parameters obtained. We determined the correlation between arylesterase activity of PON1 and SBP, DBP, BMI, glucose, T-C, HDL-C, LDL-C, TG, Hcy, hsCRP, and other laboratory parameters using the Spearman's correlation coefficient. Descriptive statistics are expressed as a median and interquartile range. In all analyses, $P$ values $<0.05$ were considered significant.

\section{RESULTS}

The demographic data, blood pressure values, and laboratory characteristics of the studied groups are summarized in table 2.

The study groups did not differ according to age, BMI, and the concentrations of fasting plasma glucose, total cholesterol, HDL-cholesterol, LDL-cholesterol, hsCRP, creatinine, and electrolytes, as well as complete blood count.

Systolic and diastolic blood pressure values differentiated the study participants by definition. Otherwise, the study groups varied in TG and Hcy concentrations, and the highest levels of these parameters were observed in patients with poorly controlled hypertension.

Arylesterase PON1 activity in patients with well controlled hypertension and in patients with newly diagnosed hypertension differed significantly from those in the control group. The subjects with newly diagnosed hypertension had the lowest activity of PON1. In turn, in patients with well controlled hypertension the highest activity of PON1 was observed (Figure 1).

In the control group, the negative correlations between the activity of PON1 and BMI (body mass index) were observed. In groups of patients with hypertension significant correlations between the activity of PON1 and SBP, DBP, and hsCRP were found (Table 3).

\section{DISCUSSION}

Paraoxonase is one of the enzymes presented for high-density lipoprotein and associated with HDL antioxidant function, thus may prevent the development of atherosclerosis [6]. The properties of PON1 make the protection of either LDL or HDL possible [5]. HDL particles deprived of PON1, naturally or by gene-knockout, were unable to inhibit the oxidation of LDL particles in the experimental study [7]. Besides, that enzyme lowers the oxidative status of macrophages, stimulates cholesterol release from macrophages, and lowers the oxidative potential of lipids, which form atherosclerotic plaque [8]. Many epidemiological studies published the significant relationship between low PON1 activity and cardiovascular diseases [9, 10]. Recently, Kunutsor et al. showed the correlation of PON1 activity and the risk of cardiovascular disease, partially dependent on the concentration of HDL-C [11]. In turn, Zhou et al. examined patients with atherosclerosis and coronary syndrome and suggested that PON1 activity may become a potential marker of the severity of coronary 
Table 2. Clinical and laboratory characteristics of the study groups. All data are presented as median and interquartile range

\begin{tabular}{|c|c|c|c|c|}
\hline Variable & $\begin{array}{c}\text { Control group } \\
(0) \\
n=28\end{array}$ & $\begin{array}{l}\text { Patients with newly diagnosed } \\
\text { hypertension } \\
\text { (1) } \\
n=25\end{array}$ & $\begin{array}{l}\text { Patients with poorly controlled } \\
\text { hypertension } \\
(2) \\
n=26\end{array}$ & $\begin{array}{c}\text { Patients with well controlled } \\
\text { hypertension } \\
(3) \\
n=25\end{array}$ \\
\hline Gender F/M & $F=13 M=15$ & $F=8 M=17$ & $\mathrm{~F}=11 \mathrm{M}=15$ & $F=6 M=19$ \\
\hline Age, years & $55.0(43.5-59.5)$ & $57.0(49.0-62.0)$ & $57.0(43.0-65.0)$ & $59.0(54.0-63.0)$ \\
\hline $\mathrm{BMI}, \mathrm{kg} / \mathrm{m}^{2}$ & $27.50(24.83-31.07)$ & $29.54(26.23-31.83)$ & $30.99(26.47-33.74)$ & $32.05(27.77-35.26)$ \\
\hline $\mathrm{SBP}, \mathrm{mmHg}$ * & $121(110-130)$ & $148(142-156)$ & $149(140-165)$ & $128(120-135)$ \\
\hline DBP, $\mathrm{mmHg}$ * & $79(70-82)$ & $94(89-98)$ & $90(90-100)$ & $80(70-88)$ \\
\hline PON1, U/ml * & $1.39(1.19-1.72)$ & $0.95(0.58-1.19)$ & $1.73(1.37-2.02)$ & $1.86(1.74-2.35)$ \\
\hline Glucose, $\mathrm{mmol} / \mathrm{l}$ & $5.24(4.79-5.49)$ & $5.29(4.75-5.64)$ & $5.18(4.97-5.70)$ & $5.33(5.03-5.74)$ \\
\hline $\mathrm{T}-\mathrm{C}, \mathrm{mmol} / \mathrm{l}$ & $5.25(4.64-6.02)$ & $5.39(5.12-6.21)$ & $5.45(4.32-6.24)$ & $5.32(4.87-6.25)$ \\
\hline $\mathrm{HDL}-\mathrm{C}, \mathrm{mmol} / \mathrm{l}$ & $1.37(1.22-1.85)$ & $1.43(1.28-1.69)$ & $1.29(1.08-1.64)$ & $1.33(0.99-1.49)$ \\
\hline $\mathrm{LDL}-\mathrm{C}, \mathrm{mmol} / \mathrm{l}$ & $3.31(2.63-4.10)$ & $3.46(2.94-4.02)$ & $3.41(2.65-3.93)$ & $3.26(2.93-4.35)$ \\
\hline $\mathrm{TG}, \mathrm{mmol} / \mathrm{l}$ * & $1.28(0.83-1.73)$ & $1.55(1.14-1.83)$ & $1.85(1.25-2.76)$ & $1.47(1.16-1.94)$ \\
\hline Hcy, $\mu \mathrm{mol} / / I^{*}$ & $13.40(9.85-16.16)$ & $15.90(13.70-19.20)$ & $16.60(13.80-18.24)$ & $15.60(13.15-20.70)$ \\
\hline hsCRP, mg/l & $1.25(0.80-2.20)$ & $1.40(0.60-2.10)$ & $2.35(1.20-3.80)$ & $2.50(1.10-4.30)$ \\
\hline Creatinine, $\mathrm{mmol} / \mathrm{l}$ & $75.00(68.30-79.10)$ & $77.00(69.80-87.00)$ & $78.50(65.00-89.70)$ & $77.00(72.30-88.00)$ \\
\hline Sodium, mmol/l & $142.0(142.0-143.0)$ & $142.0(142.0-143.0)$ & $142.0(141.0-143.0)$ & $141.0(140.0-143.0)$ \\
\hline Potassium, mmol/l & $4.30(4.20-4.50)$ & $4.20(4.10-4.40)$ & $4.20(4.00-4.50)$ & $4.40(4.20-4.60)$ \\
\hline WBC, G/I & $6.53(5.55-7.25)$ & $6.49(5.64-7.29)$ & $7.46(6.22-8.30)$ & $7.07(5.81-8.56)$ \\
\hline PLT, G/l & $224.0(184.0-266.0)$ & $225.0(209.0-274.0)$ & $227.0(214.0-251.0)$ & $236.0(174.5-255.5)$ \\
\hline RBC, $T / l$ & $4.62(4.43-4.85)$ & $4.84(4.63-5.13)$ & $4.90(4.78-5.11)$ & $4.79(4.61-5.11)$ \\
\hline $\mathrm{HCT}, \mathrm{I} / \mathrm{I}$ & $0.42(0.40-0.44)$ & $0.44(0.42-0.45)$ & $0.43(0.41-0.46)$ & $0.44(0.41-0.46)$ \\
\hline $\mathrm{HGB}, \mathrm{mmol} / \mathrm{l}$ & $8.80(8.36-9.40)$ & $9.20(8.80-9.70)$ & $9.15(8.80-9.70)$ & $9.20(8.80-9.60)$ \\
\hline
\end{tabular}

Abbreviations: BMI - body mass index, DBP - diastolic blood pressure, F- number of female, HCT - hematocrit, HGB - hemoglobin, Hcy homocysteine, hsCRP - high sensitivity $C$ - reactive protein, $M$ - number of male, $n$ - the number of patients, PLT - platelet count, RBC- red blood cells, SBP- systolic blood pressure, T-C total cholesterol, HDL-C - high density lipoprotein cholesterol, LDL-C - low density lipoprotein cholesterol, TG - triglycerides, WBC- white blood cells; * indicates statistically significant differences $(p<0.05)$ among study groups (KruskalWallis ANOVA by Ranks) and with post hoc analysis (Dunn test) below:

SBP: (0) vs (1) $p<0,0001 ;(0)$ vs $(2) p<0,0001 ;(1)$ vs $(3) p<0,0001 ;$; 2 vs $(3) p<0,0001$;

DBP: (0) vs (1) $p<0,0001$; (0) vs (2) $p<0,0001$; (1) vs (3) $p<0,0001$; (2) vs $(3) p<0,0001$;

TG: (0) vs (2) $p=0,0174$;

Hcy: (0) vs (1) $p=0,0246 ;(0)$ vs (2) $p=0,0490$

syndrome [12]. The PON1 activity could change because of vascular surgery, for example after carotid artery stenting [13]. Decreased activity of PON1 was noticed by Chen et al. in patients with primary hypertension [14]. In our study we confirmed this date for patients with newly diagnosed disease before therapy.

The results of the experimental studies showed that PON1 activity in HDL might be related to the occurrence 
Table 3. Relationships of PON1 with selected parameters in the studied groups; Spearman's correlation coefficient is presented if statistically significant $(p<0.05)$

\begin{tabular}{|c|c|c|c|c|c|c|c|}
\hline Parameters & $\begin{array}{c}\text { All study popula- } \\
\text { tion } \\
\begin{array}{c}(0)+(1)+(2)+(3) \\
n=104\end{array}\end{array}$ & $\begin{array}{c}\text { Control group } \\
(0) \\
n=28\end{array}$ & $\begin{array}{c}\text { Patients diag- } \\
\text { nosed with hyper- } \\
\text { tension } \\
(1)+(2)+(3) \\
n=76\end{array}$ & $\begin{array}{l}\text { Patients treated } \\
\text { for hypertension } \\
\qquad \begin{array}{c}(2)+(3) \\
n=51\end{array}\end{array}$ & $\begin{array}{c}\text { Patients with } \\
\text { newly diagnosed } \\
\text { hypertension (1) } \\
n=25\end{array}$ & $\begin{array}{c}\text { Patients with } \\
\text { poorly controlled } \\
\text { hypertension } \\
(2) \\
n=26\end{array}$ & $\begin{array}{c}\text { Patients with well } \\
\text { controlled } \\
\text { hypertension } \\
(3) \\
n=25\end{array}$ \\
\hline SBP & -0.2458 & ns & -0.4551 & -0.3710 & ns & ns & ns \\
\hline DBP & $-0,2650$ & ns & $-0,3877$ & ns & ns & ns & ns \\
\hline BMI & ns & -0.4246 & ns & ns & ns & ns & ns \\
\hline hsCRP & 0.2077 & ns & 0.2818 & ns & 0.4232 & ns & ns \\
\hline Glucose & ns & ns & ns & ns & ns & ns & $\mathrm{ns}$ \\
\hline $\mathrm{T}-\mathrm{C}$ & ns & ns & ns & ns & ns & ns & ns \\
\hline HDL-C & ns & ns & ns & ns & ns & ns & ns \\
\hline LDL-C & ns & ns & ns & ns & ns & ns & ns \\
\hline TG & ns & ns & ns & ns & ns & ns & ns \\
\hline Hcy & ns & ns & ns & ns & ns & ns & ns \\
\hline
\end{tabular}

SBP - systolic blood pressure, DBP - diastolic blood pressure, BMI - body mass index, hsCRP - high sensitivity C-reactive protein, T-C total cholesterol, HDL-C- high density lipoprotein cholesterol, LDL-C - low density lipoprotein cholesterol, TG- triglicerydes, Hcy- homocysteine, ns- non significant.

of hypertension [4]. The anti-atherosclerotic action of $\mathrm{HDL}$ on vascular endothelium is well known. One of the effects of $\mathrm{HDL}$ is the activation of endothelial nitric oxide synthase (eNOS), which leads to increase in the concentration of this mediator. In the vascular system, NO shows anti-coagulant, anti-inflammatory, and mostly vasorelaxant action - factors affecting blood pressure. The activity of eNOS is regulated by calcium concentration, interactions with proteins, and multi-level phosphorylations. The state of phosphorylations of the specific serine, threonine, and tyrosine residues in the enzyme molecule plays an essential role in the regulation of eNOS activity. Molecular research also showed that HDL stimulates NO production through signaling pathways leading to activation of protein eNOS phosphorylation (Ser1177) and dephosphorylation at a breaking point (Thr495) [15].

However, in studies on endothelial cell cultures, such activity was demonstrated by HDL molecules of healthy individuals $[15,16]$. HDL obtained from patients with cardiovascular diseases were dysfunctional. Binding to endothelial receptor LOX-1 (lectin-like oxidized LDL receptor-1) and activating $\mathrm{PKC} \beta \mathrm{II}$ (protein kinase $C \beta \mathrm{II}$ ), influences signaling pathways associated with protein eNOS phosphorylation in Thr place (495) and inhibits the production of nitric oxide.

The investigations of Besler et al. confirmed that the activity of PON1 related to HDL is a crucial feature for the regulation of eNOS activity. HDL derived from healthy organisms with chemically inhibited PON1 did not stimulate the active eNOS in Ser1177 phosphorylation and significantly increased the phosphorylation inhibiting NOS in Thr495. At the same time, inactivation of PON1 resulted in the loss of HDL ability to stimulate NO production in endothelial cells [15].

Low PON1 activity may contribute to endothelial dysfunction and impaired vasodilatation [17]. Chen et al. demonstrated a significant decrease in PON1 protein concentration in hypertensive patients [14]. Our results showed the reduced PON1 activity in serum of patients with newly diagnosed hypertension only. Adams et al. published that lowered HDL-related eNOS activity might contribute to increased coronary heart disease and its complications [18]. Our patients did not have any clinical signs of heart disease or any complications. Moreover, we made an effort to recruit participants with comparable basic metabolic parameters for the study.

What was interesting in our results was that in the serum of well controlled patients the activity of PON1 was significantly higher. It can be assumed that the treatment not only normalized blood pressure but also positively influenced the antioxidative function of HDL.

There are reports available on this topic. Ayashietal. proved the efficiency of carvedilol (non-selective third generation beta blocker) not only in the treatment of hypertension but also in the increase in the concentration of HDL-C and the activity of PON1 [19]. On the other hand, primary higher serum PON1 activity may lead to greater benefit from anti- 
hypertension treatment in patients. This effect can be a result of genetic predisposition: the extent to which the potential function of paraoxonase is highly dependent on genetic background [20]. The benefit of antihypertensive therapy was also proved for the glutathione-related antioxidant defense system in a context of cardiovascular disease [21].

There are no clear data on the relationships between lipid levels and PON1 activity in the serum [22]. The Iran study did not show significant differences in PON1 activity and concentrations of HDL-C and LDL-C in the serum of patients with cardiovascular diseases and healthy individuals [23]. In turn, Göçmen et al. reported on the relationship between low PON1 activity and low HDL-C, high LDL-C, and high T-C/ HDL-C ratio [24]. Other investigators observed the negative correlation between PON1 activity and the concentration of T-C and TG [25], similar to our results. Kunutsor et al. discovered the weak relationship between PON1 activity and HDL-C [11], while Zhou et al. stated the positive correlation between PON1 activity and HDL-C and ApoAI concentrations [12]. These observations suggest that lipid disorders may influence the PON1 activity in patients with cardiovascular diseases. However, in patients with hypertension, no significant correlation of arylesterase activity of PON1 and lipid parameters was observed. Due to the fact that PON1 is an integral element of $\mathrm{HDL}$, at least a relationship between the concentration of HDL-C and the activity of this enzyme would be expected. However, the content of cholesterol in this fraction does not have to be closely related to the number of protein components, and especially with the enzyme's activity. In recent years, a well documented hypothesis occurred that the metabolic effect of HDL is not reserved to cholesterol content. Other elements and their activities, such as ApoA-I (apolipoprotein A-I), ApoA-II (apolipoprotein A-II), GPx (glutathione peroxidase), LCAT (lecithin-cholesterol acyltransferase), CEPT (cholesteryl ester transfer protein), and PON1 contribute to the protective function of HDL. The "functionality" of HDL and necessity of further research on this fraction and impact of metabolic factors is frequently discussed [22, 26].

In our study, in the control group the significant negative correlation between the activity of PON1 and BMI was observed. Such relationship was absent in patients with arterial hypertension. However, other authors noted correlations between PON1 activity and HDL-C, TG, or BMI in persons with cardiovascular risk factors [27], also with arterial hypertension [10, 11, 14, 28]. In our study the positive correlation between PON1 and CRP was observed, especially in the group with newly diagnosed hypertension. In patients under antihypertensive therapy, well and poorly controlled, the effect of low-grade inflammation was not evident. The relationship between activity of PON1 and markers of lowgrade inflammation are under investigation [12, 29].
The adverse impact of homocysteine on the HDL metabolism was indicated by significant, negative correlation of Hcy and ApoA-I and HDL-C concentrations [30, 31]. We obtained similar results in our previous study of patients with primary hypertension [32]. Experimental studies proved that thiolactone derived from homocysteine might lower the activity of PON1 correlated with HDL particles. That was evidenced by Ferretti et al. who incubated HDL isolated from serum, with homocysteine thiolactone. As a result, the increase of the level of sulphydryl groups in HDL particles, correlated with the decrease of PON1 activity, was observed [33]. Besides, hyperhomocysteinemia decreases the gene expression for ApoA-I, which stabilizes PON1 in the HDL particle [34].

Perła-Kaján and Jakubowski suggested a relationship between Hcy metabolism and PON1 activity in the atherosclerosis pathogenesis [35]. They proposed homocysteine thiolactone to be the endogenous metabolite for PON1. This finding could explain why the activity of PON1, linked with the hydrolysis of this compound, prevents the $\mathrm{N}$-homocysteinylation of proteins, thus protecting them against structural and functional damage. The results of several clinical trials confirmed the relationship of homocysteine metabolism to paraoxonase activity observed in experimental studies. Locsey et al. found a negative correlation between PON1 activity and serum Hcy in patients who underwent kidney transplant [36]. In turn, Karikas et al. revealed a weak negative correlation between Hcy concentration and PON1 activity in preschool children [37]. Our study did not show any relationship between PON1 activity and Hcy in patients with hypertension. The paper by Holven et al. showed that the impact of Hcy on the metabolism and function of proteins depends on its concentration in serum [38]. It can be assumed that high levels of Hcy could cause increased oxidative stress. Chemical modification with Hcy and its derivatives reduces the activity of enzymatic antioxidants, including PON1 [33]. In the case of PON1, differences in the activity correlated with its substrate specificity should also be taken into consideration. Tang et al. conclude that arylesterase activity of PON1 is a better prognostic factor of cardiovascular risk than paraoxonase activity of the enzyme [39]. However, several investigators suggest that its activity on homocysteine thiolactone is worth investigating [40].

\section{Limitations of the study}

The activity of PON-1 may depend on many factors such as genetic polymorphism, diet, lifestyle, and medications used [4]. In our study, we focused on the effect of antihypertensive therapy. Table 1 lists the applied antihypertensive medicines taken by the patients studied. We did not analyze 
polymorphism of the PON-1 gene and the effects of diet. A large prospective study would be required to take all mentioned factors into account; the result of the statistical calculations would then be valid. Such a plan exceeded the ability of our project.

\section{CONCLUSIONS}

Effective treatment of hypertension could result in increased PON1 activity, despite unfavorable homocysteine concentrations in blood. Untreated hypertension might affect decreased activity of PON.

\section{Author's contribution}

A.B.: Research concept and design, supervising the project, carrying out the experiments, acquisition of data, analysis and interpretation of data, designing the figures, drafting the article or revising it critically for important intellectual content, writing the manuscript, literature review, final proofreading and approval of the version for publication; E.W.: Research concept and design, supervising the project, analysis and interpretation of data, designing the figures, drafting the article or revising it critically for important intellectual content, writing the manuscript, final proofreading and approval of the version for publication; A.P.: Acquisiton of data, writing the manuscript, literature review; A.T.: Carrying out the experiments, analysis and interpretation of data, literature review; A.D.: Carrying out the experiments, writing the manuscript, literature review; K.H.: Acquisition of data, writing the manuscript, literature review; S.M.: Carrying out the experiments, analysis and interpretation of data, drafting the article or revising it critically for important intellectual content; W.B.: Research concept and design, analysis and interpretation of data, writing the manuscript.

\section{Conflict of Interest}

The authors have no potential conflicts of interest to declare.

\section{Ethics Approval}

The study protocol was accepted by the Bioethics Committee of Poznan University of Medical Sciences, Poland (statement No. 55/15), according to the Declaration of Helsinki for Human Research.

\section{References}

[1] Brzyżkiewicz H., Konduracka E., Gajos G., Janion M.: Incidence of chronic heart failure with preserved left ventricular ejection fraction in patients with hypertension and isolated mild diastolic dysfunction. Pol. Arch. Med. Wewn., 2016; 126: 12-18.

[2] Czarnecka D., Jankowski P., Kopeć G., Pająk A., Podolec J., Zdrojewski T., Drygas W., Małecki M., Nowicka G., Windak A., et al.: Polish Forum for Prevention Guidelines on Hypertension: Update 2017. Kardiol. Pol., 2017; 75: 282-285.

[3] Eren E., Yilmaz N., Aydin O., Ellidağ H.Y.: Anticipatory role of high density lipoprotein and endothelial dysfunction: An overview. Open. Biochem. J., 2014; 8: 100-106.

[4] Banaszewska A., Baszczuk A., Kopczyński Z., Thielemann A., Kopczyński P.: The role of paraoxonase 1 (EC 3.1.8.1) in the development of atherosclerosis. Post. Biol. Kom., 2014; 41: 429-444.

[5] Aviram M., Rosenblat M., Bisgaier C.L., Newton R.S., Primo-Parrno S.L., La Du B.N.: Paraoxonase inhibits high-density lipoprotein oxidation and preserves its functions. A possible peroxidative role for paraoxonase. J. Clin. Invest., 1998; 101: 1581-1590.

[6] Hine D., Mackness B., Mackness M.: Coincubation of PON1, APO $A 1$, and LCAT increases the time HDL is able to prevent LDL oxidation. IUBMB Life, 2012; 64: 157-161.

[7] Shih D.M., Gu L., Xia Y.R., Navab M., Li W.F., Hama S., Castellani L.W., Furlong C.E., Costa L.G., Fogelman A.M., Lusis A.J.: Mice lacking serum paraoxonase are susceptible to organophosphate toxicity and atherosclerosis. Nature, 1998; 394: 284-287.

[8] Tavori M., Aviram S., Khatib S., Musa R., Nitecki S., Hoffman A., Vaya J.: Human carotid atherosclerotic plaque increases oxidative state of macrophages and low-density lipoproteins, whereas paraoxonase 1 (PON1) decreases such atherogenic effects. Free Radic. Biol. Med., 2009; 46: 607-615.

[9] Shunmoogam N., Naidoo P., Chilton R.: Paraoxonase (PON)-1: A brief overview on genetics, structure, polymorphisms and clinical relevance. Vasc. Health Risk Manag., 2018; 14: 137-143.

[10] Zhao Y., Ma Y., Fang Y., Liu L., Wu S., Fu D., Wang X.: Association between PON1 activity and coronary heart disease risk: A meta-analysis based on 43 studies. Mol. Genet. Metab., 2012; 105: 141-148.

[11] Kunutsor S.K., Bakker S.J., James R.W., Dullaart R.P.: Serum paraoxonase-1 activity and risk of incident cardiovascular disease: The PREVEND study and meta-analysis of prospective population studies. Atherosclerosis, 2016; 245: 143-154.

[12] Zhou C., Cao J., Shang L., Tong C., Hu H., Wang H., Fan D., Yu H.: Reduced paraoxonase 1 activity as a marker for severe coronary artery disease. Dis. Markers, 2013; 35: 97-103.

[13] Michalak S., Ambrosius W., Wysocka E., Dziarmaga M., Juszkat R., Wykretowicz A., Kozubski W.: The early effect of carotid artery stenting on antioxidant capacity and oxidative stress in patients with carotid artery stenosis. Oxid. Med. Cell. Longev., 2016; 2016: 1789596 
[14] Chen X., Wu Y., Liu L., Su Y., Peng Y., Jiang L., Liu X., Huang D.: Relationship between high density lipoprotein antioxidant activity and carotid arterial intima-media thickness in patients with essential hypertension. Clin. Exp. Hypertens., 2010; 32: 13-20.

[15] Besler C., Heinrich K., Rohrer L., Doerries C., Riwanto M., Shih D.M., Chroni A., Yonekawa K., Stein S., Schaefer N., et al.: Mechanisms underlying adverse effects of HDL on eNOS-activating pathways in patients with coronary artery disease. J. Clin. Invest., 2011; 121: 2693-2708.

[16] Xu S., Ogura S., Chen J., Little P.J., Moss J., Liu P.: LOX-1 in atherosclerosis: Biological functions and pharmacological modifiers. Cell. Mol. Life Sci., 2013; 70: 2859-2872.

[17] Charakida M., Besler C., Batuca J.R., Sangle S., Marques S., Sousa M., Wang G., Touisoulis D., Alves J.D., Loukogeorgakis S.P., et al.: Vascular abnormalities, paraoxonase activity, and dysfunctional HDL in primary antiphospholipid syndrome. JAMA, 2009; 302: 1210-1217.

[18] Adams V., Besler C., Fischer T., Riwanto M., Noack F., Höllriegel R., Oberbach A., Jehmlich N., Völker U., Winzer E.B., et al.: Exercise training in patients with chronic heart failure promotes restoration of high-density lipoprotein functional properties. Circ. Res., 2013; 113: 1345-1355.

[19] Ayashi S., Assareh A.R., Jalali M.T., Olapour S., Yaghooti H.: Role of antioxidant property of carvedilol in mild to moderate hypertensive patients: A prospective open-label study. Indian. J. Pharmacol., 2016; 48: 372-376.

[20] Fridman O., Gariglio L., Riviere S., Porcile R., Fuchs A., Potenzoni M.: Paraoxonase 1 gene polymorphisms and enzyme activities in coronary artery disease and its relationship to serum lipids and glycemia. Arch. Cardiol. Mex., 2016; 86: 350-357.

[21] Rybka J., Kupczyk D., Kędziora-Kornatowska K., Motyl J., Czuczejko J., Szewczyk-Golec K., Kozakiewicz M., Pawluk H., Carvalho L.A., Kędziora J.: Glutathione-related antioxidant defense system in elderly patients treated for hypertension. Cardiovasc. Toxicol., 2011; 11: 1-9.

[22] Mineo C., Shaul P.W.: PON-dering differences in HDL function in coronary artery disease. J. Clin. Invest., 2011; 121: 2545-2548.

[23] Rahmani M., Raiszadeh F., Allahverdian S., Kiaii S., Navab M., Azizi F.: Coronary artery disease is associated with the ratio of apolipoprotein A-I/B and serum concentration of apolipoprotein B, but not with paraoxonase enzyme activity in Iranian subjects. Atherosclerosis, 2002; 162: 381-389.

[24] Göçmen A.Y., Gümüşlü S., Semiz E.: Association between paraoxonase-1 activity and lipid peroxidation indicator levels in people living in the Antalya region with angiographically documented coronary artery disease. Clin. Cardiol., 2004; 27: 426-430.

[25] Shekhanawar M., Shekhanawar S.M., Krisnaswamy D., Indumati V., Satishkumar D., Vijay V., Rajeshwari T., Amareshwar M.: The role of "paraoxonase-1 activity" as an antioxidant in coronary artery diseases. J. Clin. Diagn. Res., 2013; 7: 1284-1287.

[26] Yan L.R., Wang D.X., Liu H., Zhang X.X., Zhao H., Hua L., Xu P., Li Y.S.: A pro-atherogenic HDL profile in coronary heart disease patients: An iTRAQ labelling-based proteomic approach. PLoS One, 2014; 9: e98368.

[27] Alaminos-Castillo M.Á., Ho-Pagaro A., García-Serrano S., Santiago-Fernandez C., Rodríguez-Pacheco F., Garrido-Sanchez L., Rodriguez C., Valdes S., Gonzalo M., Moreno-Ruiz F.J., et al.: Increased PON lactonase activity in morbidly obese patients is associated with impaired lipid profile. Int. J. Clin. Pract., 2019; 73: e13315.

[28] Aslan M., Horoz M., Sabuncu T., Celik H., Selek S.: Serum paraoxonase enzyme activity and oxidative stress in obese subjects. Pol. Arch. Med. Wewn., 2011; 121: 181-186.

[29] van Himbergen T.M., Roest M., de Graaf J., Jansen E.H., Hattori H., Kastelein J.J., Voorbij H.A., Stalenhoef A.F., van Tits L.J.: Indications that paraoxonase-1 contributes to plasma high density lipoprotein levels in familial hypercholesterolemia. J. Lipid Res., 2005; 46: 445-451.

[30] Daly C., Fitzgerald A.P., O'Callaghan P., Collins P., Cooney M.T., Graham I.M., COMAC Group.: Homocysteine increases the risk associate with hyperlipidaemia. Eur. J. Cardiovasc. Prev. Rehabil., 2009; 16: 150-155.

[31] Guéant-Rodriguez R.M., Spada R., Moreno-Garcia M., Anello G., Bosco P., Lagrost L., Romano A., Elia M., Guéant J.L.: Homocysteine is a determinant of ApoA-I and both are associated with ankle brachial index, in an ambulatory elderly population. Atherosclerosis, 2011; 214: 480-485.

[32] Baszczuk A., Musialik K., Kopczyński J., Thielemann A., Kopczyński Z., Kęsy L., Dopierała G.: Hyperhomocysteinemia, lipid and lipoprotein disturbances in patients with primary hypertension. Adv. Med. Sci., 2014; 59: 68-73.

[33] Ferretti G., Bacchetti T., Marotti E., Curatola G.: Effect of homocysteinylation on human high-density lipoproteins: A correlation with paraoxonase activity. Metabolism, 2003; 52: 146-151.

[34] Liao D., Tan H., Hui R.,, Li Z., Jiang X., Gaubatz J., Yang F., Durante W., Chan L., Schafer A.I., et al.: Hyperhomocysteinemia decreases circulating high-density lipoprotein by inhibiting apolipoprotein A-I protein synthesis and enhancing HDL cholesterol clearance. Circ. Res., 2006; 99: 598-606.

[35] Perła-Kaján J., Jakubowski H.: Paraoxonase 1 and homocysteine metabolism. Amino Acids, 2012; 43: 1405-1417.

[36] Locsey L., Seres I., Sztanek F., Harangi M., Padra J., Kovacs D., Fedor R., Asztalos L., Paragh G.: Relationship between serum paraoxonase and homocysteine thiolactonase activity, adipokines, and asymmetric dimethyl arginine concentrations in renal transplant patients. Transplant. Proc., 2013; 45: 3685-3687.

[37] Karikas G.A., Kriebardis A., Samara I., Schulpis K., Papachristodoulou M., Fytou-Pallikari A.: Serum homocysteine levels and paraoxonase 1 activity in preschool aged children in Greece. Clin. Chem. Lab. Med., 2006; 44: 623-627.

[38] Holven K.B., Aukrust P., Retterstøl K., Otterdal K., Bjerkeli V., Ose L., Nenseter M.S., Halvorsen B.: The antiatherogenic function of HDL is impaired in hyperhomocysteinemic subjects. J. Nutr., 2008; 138: 2070-2075. 
[39] Tang W.H., Hartiala J., Fan Y., Wu Y., Stewart A.F., Erdmann J., Kathiresan S., CARDIoGRAM Consortium, Roberts R., McPherson R., et al.: Clinical and genetic association of serum paraoxonase and arylesterase activities with cardiovascular risk. Arterioscler. Thromb. Vasc. Biol., 2012; 32: 2803-2812.

[40] Abelló D., Sancho E., Camps J., Joven J.: Exploring the role of paraoxonases in the pathogenesis of coronary artery disease: A systematic review. Int. J. Mol. Sci., 2014; 15: 20997-21010. 